\title{
XPS and Electron Microscopy Study of Oxide-Scale Evolution on Ignition Resistant Mg-3Ca Alloy at Low and High Heating Rates
}

\author{
L. A. Villegas-Armenta ${ }^{1, *}$ (D, R. A. L. Drew ${ }^{2}$ and M. O. Pekguleryuz ${ }^{1}$ \\ ${ }^{1}$ Department of Mining and Materials Engineering, McGill University, 3610 University, Montreal, Quebec, CanadaH3A 2B2, \\ and ${ }^{2}$ Department of Mechanical, Industrial and Aerospace Engineering, Concordia University, 1515 Ste Catherine O, Montreal, \\ Quebec, Canada H3G 1M8 \\ *Corresponding author: luis.villegasarmenta@mail.mcgill.ca
}

(Received 22 June 2020; Revised 23 July 2020; Accepted 11 August 2020)

\begin{abstract}
Earlier work by the authors suggested that the formation of molten eutectic regions in Mg-Ca binary alloys caused a discrepancy in ignition temperature when different heating rates are used. This effect was observed for alloys where Ca content is greater than $1 \mathrm{wt} \%$. In this work, the effect of two heating rates $\left(25^{\circ} \mathrm{C} / \mathrm{min}\right.$ and $45{ }^{\circ} \mathrm{C} / \mathrm{min}$ ) on the ignition resistance of $\mathrm{Mg}$-3 Ca is evaluated in terms of oxide growth using X-ray Photoelectron Spectroscopy. It is found that the molten eutectic regions develop a thin oxide scale of $\sim 100 \mathrm{~nm}$ rich in $\mathrm{Ca}$ at either heating rate. The results prove that under the high heating rate, solid intermetallics are oxidized forming $\mathrm{CaO}$ nodules at the metal/oxide interface that eventually contribute to the formation of a thick and non-protective oxide scale in the liquid state.
\end{abstract}

\section{Introduction}

The development of ignition-resistant magnesium $(\mathrm{Mg})$ alloys for cabin components of commercial planes has gained a renewed interest since their ban was lifted in an update of the SAE aerospace standard AS8049C (Gwynne, 2015) in 2014. The use of Ca to increase ignition resistance has been particularly preferred for both commercial and experimental alloys (Sakamoto et al., 1997; Shih et al., 2004; Tekumalla \& Gupta, 2017; Villegas-Armenta \& Pekguleryuz, 2020). However, some underlying mechanisms such as the sensitivity of ignition temperature $\left(T_{i}\right)$ to heating rate and the effect of microstructure evolution have been missing. The main factor driving ignition resistance, is the slowing down of $\mathrm{Mg}$ oxidation, which increases the surface temperature drastically and leads to Mg vaporization and ignition. An earlier study by the authors (Villegas-Armenta et al., 2020) has found that the $\mathrm{T}_{\mathrm{i}}$ of Mg-2wt\%Ca and $\mathrm{Mg}-3 \mathrm{wt} \% \mathrm{Ca}$ alloys were affected by heating rate, with little to no effect on pure $\mathrm{Mg}$ and $\mathrm{Mg}-1 \mathrm{wt} \% \mathrm{Ca}$. The results showed that, unlike observations on biomass materials (Cai et al., 2018; Huang et al., 2018; Mishra \& Mohanty, 2018), where a low heating rate leads to longer oxidation times and low ignition temperature, the low heating rate in binary $\mathrm{Mg}-2 \mathrm{wt} \% \mathrm{Ca}$ and $\mathrm{Mg}-3 \mathrm{wt} \% \mathrm{Ca}$ alloys leads to a high ignition temperature. The longer time elapsed allowed the formation of molten eutectic pools covering the alloy surface, which are resistant to oxidation. A high heating rate quickly oxidizes $\mathrm{Ca}$, which forms a protective scale at first,

\footnotetext{
(C) The Author(s), 2020. Published by Cambridge University Press. This is an Open Access article, distributed under the terms of the Creative Commons Attribution licence (http://creativecommons.org/licenses/by/4.0/), which permits unrestricted re-use, distribution, and reproduction in any medium, provided the original work is properly cited.
} 
but becomes crack-prone upon thickening and leads to extensive $\mathrm{Mg}$ oxidation, vaporization and early ignition. In this paper, we present a complementary analysis of the oxide scale growth on a $\mathrm{Mg}-3 \mathrm{Ca}$ alloy during continuous heating. Two heating rates, which exhibited very drastic differences in ignition behavior, were studied.

\section{Methods}

A Mg-3Ca binary alloy was synthesized by permanent mold cast as per the method presented in (Villegas-Armenta et al., 2020). Likewise, details of sample preparation and the interrupted continuous heating tests were presented in the same work (Villegas-Armenta et al., 2020). Two different continuous heating rates were used for the interrupted tests: $25{ }^{\circ} \mathrm{C} / \mathrm{min}$ (Low Heating Rate - LHR) and $45^{\circ} \mathrm{C} / \mathrm{min}$ (High Heating Rate - HHR). The tests were interrupted at 350 (solid), 560 (semi-solid) and 700 (liquid) ${ }^{\circ} \mathrm{C}$. The chemical composition of the $\mathrm{Mg}$-3Ca alloy was determined by the NADCAP certified laboratory Genitest Inc via Inductively Coupled Plasma - Atomic Emission Spectrometry (ICPAES). The resulting composition was (in wt\%): $2.98 \mathrm{Ca}, 0.005 \mathrm{Mn}, 0.006 \mathrm{Al}, 0.003(\mathrm{Cu}, \mathrm{Ni}, \mathrm{Si}$ ) and balance Mg. Characterization was carried out using a SU3500 Hitachi Scanning Electron Microscope (SEM), a Thermo Scientific K-Alpha X-ray Photoelectron Spectroscopy (XPS) and a FEI Tecnai G ${ }^{2}$ F20 200 kV Cryo-Scanning Transmission Electron Microscope (TEM). TEM samples were extracted using a FIB-SEM Helios Nanolab 660 DualBeam. Additionally, the software CrysTBox (Klinger, 2017) was used as an auxiliary tool to define the diffraction patterns.

\section{Results}

Fig. 1 presents the heating curves Mg-3Ca samples obtained at HHR and LHR. The $\mathrm{T}_{\mathrm{i}}$ for $\mathrm{Mg}$-3Ca alloy measured previously by the authors (Villegas-Armenta et al., 2020) is also indicated in Fig. 1 for both heating rates. Fig. 2 shows the oxide scale evolution analyzed though XPS at each interrupted test. The vertical red dotted line describes the etch level at which the Mg metallic signal in the Mg KLL region was detected. This is considered to be the metal/oxide interface. Fig. 3 shows the surface of both HHR and LHR samples at $560{ }^{\circ} \mathrm{C}$. At this stage (semi-solid state) samples start displaying significant microstructural differences. The LHR sample show a widespread covering of molten and

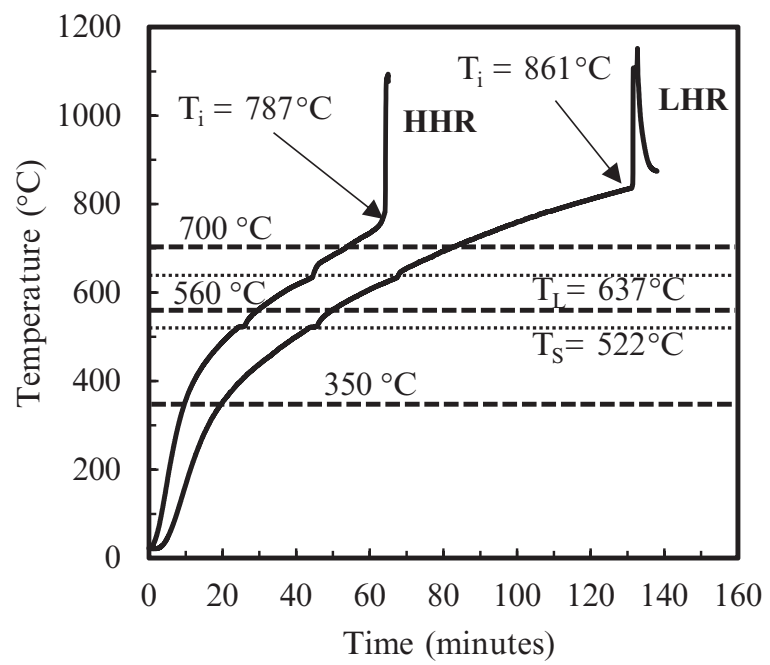

Fig. 1. Ignition curves of the Mg-3Ca alloy heated using a HHR and a LHR. The liquidus and solidus temperatures are indicated as thin dotted lines. The interrupted ignition test lines are indicated as thick dotted lines. 

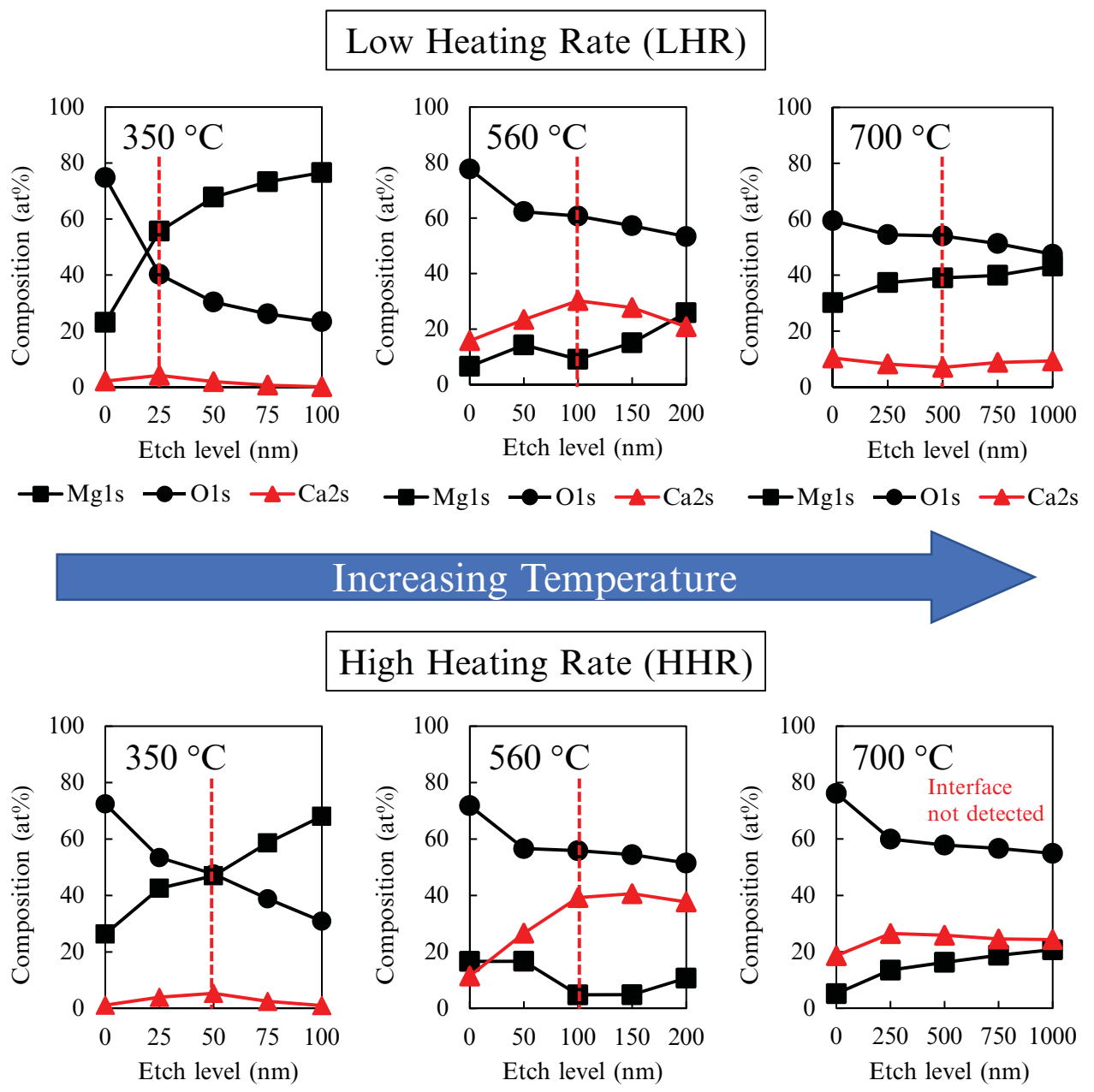

$-\mathrm{Mg} 1 \mathrm{~s} \rightarrow \mathrm{O} 1 \mathrm{~s} \rightarrow \mathrm{Ca} 2 \mathrm{~s}$

$-\mathrm{Mg} 1 \mathrm{~s}$

$-\mathrm{O} 1 \mathrm{~s} \rightarrow \mathrm{Ca} 2 \mathrm{~s}$

$-\mathrm{Mg} 1 \mathrm{~s} \rightarrow \mathrm{O} 1 \mathrm{~s} \rightarrow \mathrm{Ca} 2 \mathrm{~s}$

Fig. 2. XPS surface analysis of the HHR and LHR. Samples interrupted at 350,560 and $700^{\circ} \mathrm{C}$. The red dotted line represents the approximate position of the metal/oxide interface.

re-solidified eutectic phases while the HHR shows a more restricted covering along with internally oxidized $\mathrm{CaO}$-rich nodules coming from remaining solid intermetallics. The small micrographs on the upper right corner of each image show the cross sections extracted through FIB that were analyzed using TEM. In Fig. 4, the SAED patterns confirmed that the re-solidified intermetallics are in fact $\mathrm{Mg}_{2} \mathrm{Ca}$ using either heating rate, while the oxide scale over them is thin (80 to $110 \mathrm{~nm}$ ) and rich in $\mathrm{CaO}$ with apparently no $\mathrm{MgO}$ being formed.

XPS results indicate that $\mathrm{Ca}$ tends to be higher at the metal/oxide interface for both heating rates with a similar approximate thickness. For the HHR however, the Ca content increases significantly in the semisolid and liquid stages, confirming the previously exposed theory of profuse Ca oxidation being the driving force for early ignition (Villegas-Armenta et al., 2020). The re-solidified regions in the semi-solid state have the same characteristics regardless of the heating rate used. $\mathrm{CaO}$ nodules are formed from the solid intermetallics that oxidize in the HHR sample. In the LHR sample, the slower heating allows the partial melting of the interdendritic regions instead of their localized oxidation. 

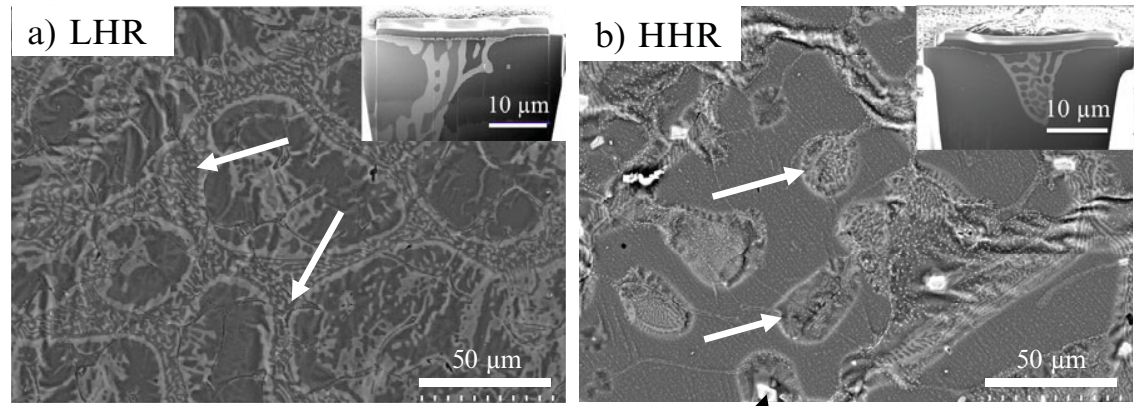

c) EDS line scan - HHR
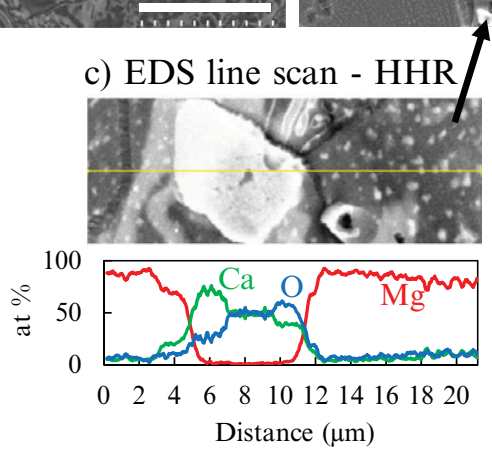

Fig. 3. SEM micrographs of the sample surface in the semi-solid state $\left(560^{\circ} \mathrm{C}\right)$ (a) LHR; (b) HHR. (c) EDS line scan of one of the oxide nodules observed in the HHR sample.
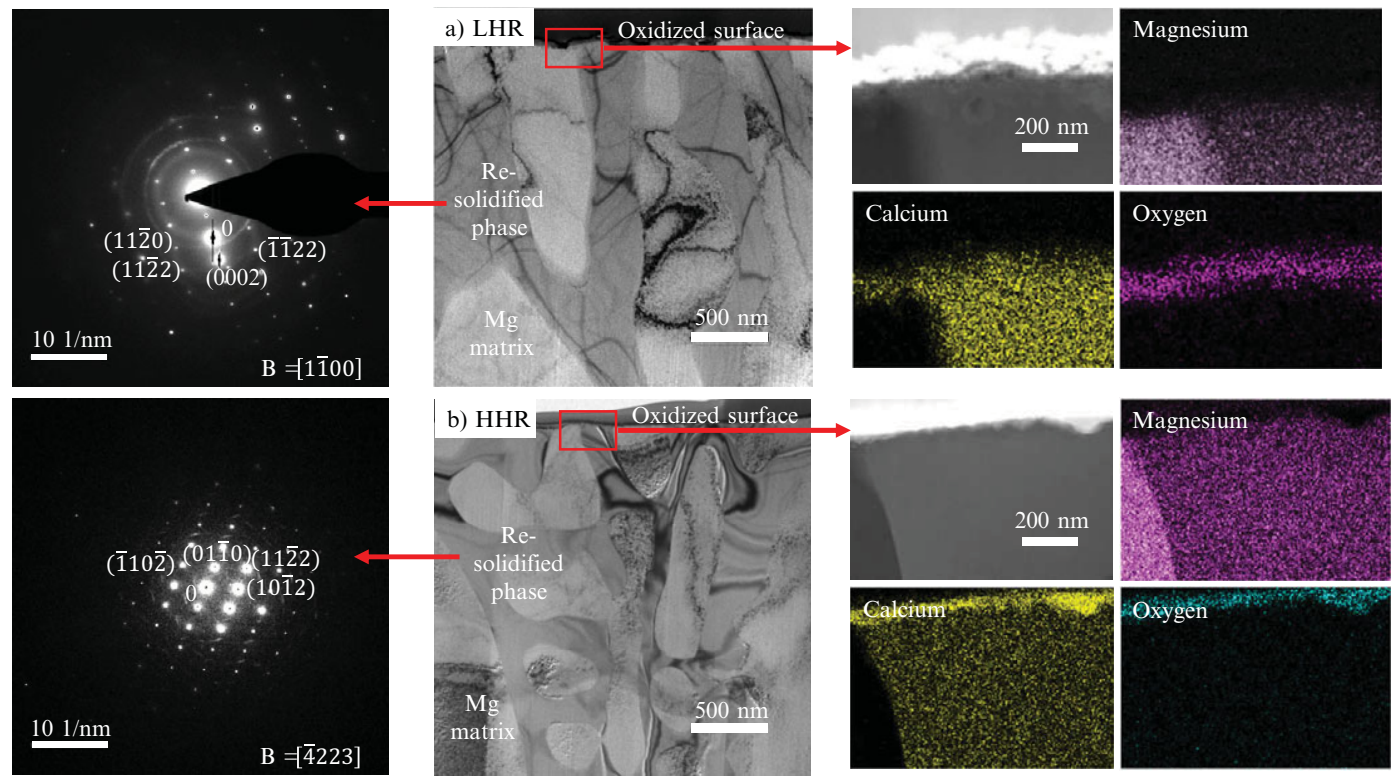

Fig. 4. TEM bright field images of FIB-extracted cross-sections for (a) LHR and (b) HHR. SAED pattern (left) of the re-solidified phase and EDS map (right) of the oxidized surface.

\section{Conclusions}

The present work confirmed the observations made previously by the authors; using XPS surface analysis to study the oxide scale growth of $\mathrm{Mg}$-3Ca alloy during ignition testing indicate that $\mathrm{Ca}$ concentrates at the metal/oxide interface. Despite both samples having similar characteristics regarding oxide 
characteristics and re-solidified phases in the semi-solid state, the internally oxidized $\mathrm{CaO}$ nodules in the HHR sample promote the formation of a thick oxide scale prone to cracking once the liquid state is reached.

Acknowledgements. The authors thanks Pierre Vermette from McGill University for his assistance in alloy making and casting and the McGill Facility for Electron Microscopy Research (FEMR), particularly to David Liu and Weawkamol Leelapornpisit, for their technical support.

Author contributions. L.A. Villegas-Armenta, M.O. Pekguleryuz and R.A.L Drew conceived and designed the study. L.A. performed the experimental work. L.A. Villegas-Armenta wrote the article while M.O. Pekguleryuz and R.A.L Drew reviewed and improved the contents.

Funding Information. This project was financially supported by the Natural Sciences and Engineering Research Council of Canada (NSERC) (M.O.P. Discovery Grant G210358NSERCRGPIN-2016-05121); and the Consejo Nacional de Ciencia, Tecnologia y Diseño (CONACYT) (L.A.V.A. Scholarship number 410607).

Conflicts of Interest. L.A. Villegas-Armenta, R. A. L. Drew and M. O. Pekguleryuz declare none.

Data availability statement. The data that support the findings of this study are available by contacting the corresponding author of this publication, upon reasonable request.

\section{References}

Cai, H., Zou, H., Liu, J., Xie, W., Kuo, J., Buyukada, M., \& Evrendilek, F. (2018). Thermal degradations and processes of waste tea and tea leaves via TG-FTIR: combustion performances, kinetics, thermodynamics, products and optimization. Bioresource Technology, 268, 715-725.

Gwynne, B. (2015). Magnesium in Aircraft Seats SAE Update, Int. Aircr. Mater. Fire Test Work. Gr. https://www.fire.tc.faa.gov/ pdf/materials/June15Meeting/Gwynne-0615-AricraftSeatsSAEUpdate.pdf

Huang, J., Liu, J., Chen, J., Xie, W., Kuo, J., Lu, X., Chang, K., Wen, S., Sun, G., Cai, H., Buyukada, M., \& Evrendilek, F. (2018). Combustion behaviors of spent mushroom substrate using TG-MS and TG-FTIR: thermal conversion, kinetic, thermodynamic and emission analyses. Bioresource Technology, 266, 389-397. https://doi.org/10.1016/j.biortech.2018.06.106.

Klinger, M. (2017). More features, more tools, more CrysTBox. Journal of Applied Crystallography, 50, 1226-1234. https:// doi.org/10.1107/S1600576717006793.

Mishra, R. K., \& Mohanty, K. (2018). Pyrolysis kinetics and thermal behavior of waste sawdust biomass using thermogravimetric analysis. Bioresource Technology, 251, 63-74. https://doi.org/10.1016/j.biortech.2017.12.029.

Sakamoto, M., Akiyama, S., \& Ogi, K. (1997). Suppression of ignition and burning of molten Mg alloys by Ca bearing stable oxide film. Journal of Materials Science Letters, 16, 1048-1050. https://doi.org/10.1023/A:1018526708423.

Shih, T. S., Wang, J. H., \& Chong, K. Z. (2004). Combustion of magnesium alloys in air. Materials Chemistry and Physics, 85, 302-309. https://doi.org/10.1016/j.matchemphys.2004.01.036.

Tekumalla, S., \& Gupta, M. (2017). An insight into ignition factors and mechanisms of magnesium based materials: a review. Materials and Design, 113, 84-98. https://doi.org/10.1016/j.matdes.2016.09.103.

Villegas-Armenta, L. A., Drew, R. A. L., \& Pekguleryuz, M. O. (2020). The ignition behavior of Mg-Ca binary alloys; the role of heating rate. Oxidation of Metals, 93, 545-558. https://doi.org/10.1007/s11085-020-09970-x.

Villegas-Armenta, L. A., \& Pekguleryuz, M. O. (2020). The ignition behavior of a ternary Mg-Sr-Ca alloy. Advanced Engineering Materials, 22, 1-8. https://doi.org/10.1002/adem.201901318.

Cite this article: Villegas-Armenta LA, Drew RAL, Pekguleryuz MO (2020). XPS and Electron Microscopy Study of OxideScale Evolution on Ignition Resistant Mg-3Ca Alloy at Low and High Heating Rates Experimental Results, 1, e37, 1-9. https:// doi.org/10.1017/exp.2020.41 


\section{Peer Reviews}

\section{Reviewing editor: Dr. Eva Unger}

Lund University, Lund, Sweden, 22100

This article has been accepted because it is deemed to be scientifically sound, has the correct controls, has appropriate methodology and is statistically valid, and has been sent for additional statistical evaluation and met required revisions.

doi:10.1017/exp.2020.41.pr1

Review 1: XPS and Electron Microscopy Study of Oxide-Scale Evolution on Ignition Resistant Mg-3Ca Alloy at Low and High Heating Rates

Reviewer: Ali Arslan Kaya

Date of review: 10 July 2020

(C) The Author(s), 2020. Published by Cambridge University Press This is an Open Access article, distributed under the terms of the Creative Commons Attribution licence (http://creativecommons.org/licenses/by/4.0/), which permits unrestricted re-use, distribution, and reproduction in any medium, provided the original work is properly cited.

Conflict of interest statement. Reviewer declares none.

Comments to the Author: This is a useful work clarifying some important details of the generally known effect of $\mathrm{Ca}$ on the ignition resistance of Ca-contaning magnesium alloys. Presenting further details, such as the microstructures prior to ignition tests and a comparison with those after the ignition tests were undertaken, would have added further value to the work. There exist a good spectrum of literature work on the effect of $\mathrm{Ca}$ addition to Magnesium. The reference list of this work may be considered somewhat short in benefiting from those reported works of others.

\section{Score Card}

Presentation

4.0

Is the article written in clear and proper English? (30\%)

Is the data presented in the most useful manner? (40\%)

Does the paper cite relevant and related articles appropriately? (30\%)

Context

Does the title suitably represent the article? (25\%)

Does the abstract correctly embody the content of the article? (25\%)

Does the introduction give appropriate context? (25\%)

Is the objective of the experiment clearly defined? (25\%) 
Analysis

Is the conclusion consistent with the results and discussion? (40\%)

Are the limitations of the experiment as well as the contributions of the experiment clearly outlined? $(20 \%)$ 


\section{Review 2: XPS and Electron Microscopy Study of Oxide-Scale Evolution on Ignition Resistant Mg-3Ca Alloy at Low and High Heating Rates}

Reviewer: Dr. Yuan Chunmiao (1D)

Date of review: 12 July 2020

(C) The Author(s), 2020. Published by Cambridge University Press This is an Open Access article, distributed under the terms of the Creative Commons Attribution licence (http://creativecommons.org/licenses/by/4.0/), which permits unrestricted re-use, distribution, and reproduction in any medium, provided the original work is properly cited.

Conflict of interest statement. Reviewer declares none

Comments to the Author: This paper gives experimental results on the oxide-scale evolution of $\mathrm{Mg}-3 \mathrm{Ca}$ Alloys. Different heating rates were discussed based on the XPS and SEM/TEM results. All conclusions made in the paper are well supported by the data presented. A minor revision is suggested before its publication.

1) The heating rate is the unique variable in this study, but only two heating rates were considered in this manuscript. Is this enough to draw a convincing conclusion?

2) Some studies (see references) indicated the lower heating rate may result in a lower ignition temperature for biomass materials due to much longer heating time and a much slower process of oxidation. This is contrary to the result in Fig. 1. It would be better to give more explanation on the ignition mechanism of $\mathrm{Mg}$ alloy.

References

Mishra, R.K., Mohanty, K., 2018. Pyrolysis kinetics and thermal behavior of waste sawdust biomass using thermogravimetric analysis. BIORESOURCE TECHNOLOGY 251, 63-74.

Cai, H., Zou, H., Liu, J., Xie, W., Kuo, J., Buyukada, M., Evrendilek, F., 2018. Thermal degradations and processes of waste tea and tea leaves via TG-FTIR_Combustion performances, kinetics, thermodynamics, products and optimization. BIORESOURCE TECHNOLOGY 268, 715-725.

Huang, J., Liu, J., Chen, J., Xie, W., Kuo, J., Lu, X., Chang, K., Wen, S., Sun, G., Cai, H., Buyukada, M., Evrendilek, F., 2018. Combustion behaviors of spent mushroom substrate using TG-MS and TG-FTIR_ Thermal conversion, kinetic, thermodynamic and emission analyses. BIORESOURCE TECHNOLOGY 266, 389-397.

\section{Score Card}

Presentation

Is the data presented in the most useful manner? (40\%)

Does the paper cite relevant and related articles appropriately? (30\%)

Context

Does the abstract correctly embody the content of the article? (25\%)

Does the introduction give appropriate context? (25\%)

Is the objective of the experiment clearly defined? (25\%) 
Analysis

Is the conclusion consistent with the results and discussion? (40\%)

Are the limitations of the experiment as well as the contributions of the experiment clearly outlined? $(20 \%)$ 